\title{
Replacement Therapy
}

National Cancer Institute

\section{Source}

National Cancer Institute. Replacement Therapy. NCI Thesaurus. Code C15471.

Administration of a body substance to compensate for the loss, as from disease or surgery, of a gland or tissue that would normally produce the substance. 